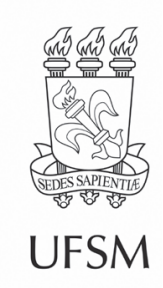

\title{
Artigos
}

\section{Variabilidade espacial da biomassa e atividade microbiana do solo sob sistema de integração lavoura- pecuária-floresta}

\author{
Spatial variability of biomass and soil microbial activity under crop- \\ livestock-forest integration system
}

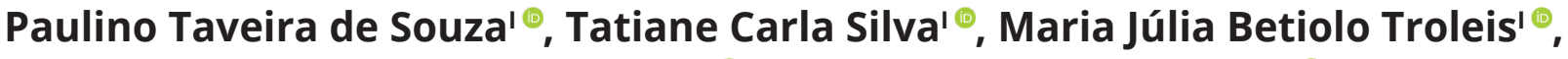 Karla Nascimento Sena ${ }^{\bullet}$, Anne Caroline Rocha Silval ${ }^{\bullet}$ Talles Eduardo Borges dos Santos" ${ }^{\circledR}$, Rafael Montanari'॰}

\author{
'Universidade Estadual Paulista "Júlio de Mesquita Filho", Ilha Solteira, SP, Brasil \\ "Universidade Estadual de Goiás, Ipameri, GO, Brasil
}

\section{RESUMO}

A qualidade do solo refere-se à avaliação das propriedades químicas, físicas e biológicas do solo e tem sido um assunto explorado dentro das linhas de pesquisas agronômicas em decorrência de ações antrópicas que, muitas vezes, causam degradação. Objetivou-se pesquisar, entre os atributos físicos e biológicos estudados, aqueles que melhor expliquem, linear e espacialmente, a variabilidade do solo cultivado com soja na estação chuvosa e em pousio na estação seca no sistema agrossilvipastoril. 0 trabalho foi conduzido no ano agrícola 2015/2016, em Ipameri, Goiás. Analisaram-se as distribuições espaciais e as correlações entre alguns atributos indicadores da qualidade do solo: carbono da biomassa microbiana (CBM), respiração microbiana do solo $\left(\mathrm{C}_{-}-\mathrm{CO}_{2}\right)$, quociente metabólico $\left(q \mathrm{CO}_{2}\right)$ e umidade do solo (UG), na profundidade de 0,00-0,10 m, nos períodos de chuva e seca. Instalou-se no local, uma malha geoestatística, onde foram coletados 52 pontos. Foi realizada a análise descritiva dos dados, a fim de obter correlações lineares, simples e múltiplas, entre os atributos. Os semivariogramas foram modelados a fim de obter as respectivas krigagens e validações cruzadas. Estabeleceram-se as co-krigagens de interesse. Os atributos microbiológicos do solo foram bons indicadores de zonas de manejo específico, apresentando maior dependência espacial no período chuvoso. $\mathrm{O} q \mathrm{CO}_{2}$ apresentou relação direta com $\mathrm{C}-\mathrm{CO}_{2}$ no período chuvoso, enquanto $\mathrm{CBM}$ apresentou relação inversamente proporcional tanto no período chuvoso, como no seco. $\mathrm{O} q \mathrm{CO}_{2}$ foi o atributo que melhor representou, linear e espacialmente, a variabilidade do solo sob o sistema ILPF, refletindo as zonas de maior eficiência do uso do substrato pelos organismos do solo.

Palavras-chave: Geoestatística; Qualidade do solo; Carbono da biomassa microbiana; Microrganismos do solo 


\section{ABSTRACT}

Soil quality refers to the assessment of the chemical, physical and biological properties of the soil and has been a subject explored within the lines of agronomic research because of anthropic actions that often cause degradation. The objective was to research, among the studied physical and biological attributes, those that best explain, linearly and spatially, the variability of the soil cultivated with soybeans in the rainy season and fallow in the dry season in the agrosilvopastoral system. The work was carried out in the 2015/2016 agricultural year, in Ipameri, Goiás. The spatial distributions and correlations between some soil quality indicator attributes were analyzed: microbial biomass carbon (CBM), soil microbial respiration $\left(\mathrm{C}-\mathrm{CO}_{2}\right)$, metabolic quotient $\left(q \mathrm{CO}_{2}\right)$ and soil moisture $(\mathrm{UG})$, at a depth of $0.00-0.10 \mathrm{~m}$, during periods of rain and drought. A geostatistical grid was installed, where 52 points were collected. Descriptive analysis of the data was carried out to obtain linear, simple and multiple correlations between the attributes. The semivariograms were modeled to obtain the respective krigings and cross-validations. The co-krigages of interest were established. The microbiological attributes of the soil were good indicators of specific management zones, showing greater spatial dependence in the rainy season. $q \mathrm{CO}_{2}$ was directly related to $\mathrm{C}-\mathrm{CO}_{2}$ in the rainy season, while $\mathrm{CBM}$ was inversely proportional in bothrainy and dry periods. The $q_{\mathrm{CO}_{2}}$ was the attribute that best represented, linearly and spatially, the variability of the soil under the ILPF system, reflecting the zones of greatest efficiency in the use of the substrate by soil organisms.

Keywords: Geoestatistics; Soil quality; Microbial biomass carbon; Soil microorganisms

\section{INTRODUÇÃO}

O solo sob cobertura vegetal natural, quando convertido em áreas agricultáveis, passa por mudanças drásticas, as quais podem interferir em sua qualidade. Esta é facilmente influenciada por sistemas de manejo, de modo que o uso inadequado do solo afeta negativamente os processos ecológicos (VINHAL-FREITAS et al. 2017). Nesse contexto, o sistema integração lavoura-pecuária-floresta (ILPF) favorece a qualidade do solo, pois a manutenção de resíduos vegetais é constante, possibilitando melhorias nas condições físico-químicas e biológicas, incorporação de matéria orgânica, além de aumentar a ciclagem e eficiência de utilização dos nutrientes (ALVARENGA et al. 2010).

A qualidade natural do solo depende da dinâmica da matéria orgânica e da ciclagem de nutrientes, ambos processos catalisados por microrganismos (ALCANTARA NETO, 2011). Estes são considerados a parte viva da matéria orgânica, responsáveis pela disponibilidade e qualidade dos nutrientes, os quais desempenham função chave em diversos processos importantes do solo como decomposição, mineralização e 
ciclagem, além de representar um importante reservatório de nutrientes (MOREIRA; SIQUEIRA, 2006), sendo a camada superficial do solo a área de maior atividade da biomassa microbiana devido à proximidade e à disponibilidade do substrato (resíduos vegetais) (SOUZA et al. 2006).

Os principais parâmetros microbiológicos utilizados como indicadores da qualidade do solo incluem a respiração microbiana do solo $\left(\mathrm{C}-\mathrm{CO}_{2}\right)$, o carbono da biomassa microbiana (CBM) e o quociente metabólico $\left(q \mathrm{CO}_{2}\right)$, utilizados como indicadores da qualidade do solo (VINHAL-FREITAS et al. 2017; MAHARJAN et al. 2017).

A biomassa microbiana reflete estresses gerados no sistema solo que afetam a densidade, a diversidade e a atividade das populações microbianas do solo (VINHALFREITAS et al.2017; MAHARJAN et al. 2017), de modo que o desenvolvimento microbiano é estimulado pela redução na acidez, aumento no carbono orgânico (deposição de material vegetal) e teor de umidade do solo (GUANGMING et al. 2017).

A respiração microbiana do solo é um dos mais antigos parâmetros para quantificar a atividade microbiana, uma vez que representa a oxidação da matéria orgânica por organismos aeróbios do solo, que utilizam $\mathrm{O}_{2}$ como aceptor final de elétrons até $\mathrm{CO}_{2}$ (MOREIRA; SIQUEIRA, 2006).

Em associação com a respiração microbiana, podemos obter o $q \mathrm{CO}_{2}$ pela razão entre a respiração microbiana por unidade de carbono da biomassa microbiana do solo e tempo, sendo utilizado para verificar a eficiência do uso do substrato pelos organismos do solo (ANDERSON; DOMSCH, 1993). Como existe uma relação inversa entre o $\mathrm{CBM}$ e o $q \mathrm{CO}_{2}$, maiores valores de CBM ocorrem na presença de elevados teores de carbono, reduzindo a atividade metabólica (INSAM, 1991).

Os atributos do solo desempenham importante papel no desenvolvimento das plantas; assim, a variabilidade espacial dos seus valores deve ser conhecida com o intuito de reduzir os vieses de amostragem e de manejo, pois o solo apresenta grande variabilidade, vertical e/ou horizontal (GAZOLA et al. 2017). Manejos conservacionistas, como a integração lavoura-pecuária-floresta, criam diferentes condições ambientais 
daquelas encontradas no preparo convencional (resultante dos efeitos dos resíduos vegetais superficiais e da reduzida movimentação do solo). Para se realizar recomendações de práticas de manejo, torna-se imprescindível o mapeamento desses atributos (CORRÊA et al. 2014).

A estatística descritiva aborda a variação das características do solo dentro das unidades amostrais, de modo que estas não se correlacionam, afirmando, assim, que a média das amostras é o melhor estimador das características de solo, na unidade amostral. Incrementos tecnológicos na agropecuária demonstram a relevância em mensurar as variações espacial e temporal em propriedades que almejem o aumento de produtividade das culturas, com o intuito de otimizar o aproveitamento de recursos e diminuir custos, criando as zonas específicas de manejo, assim, faz-se o uso da geoestatística (LIMA et al. 2017).

Diante do exposto, o presente trabalho objetivou pesquisar, entre os atributos microbiológicos e físico estudados, aqueles que melhor representem, linear e espacialmente, a variabilidade do solo sob o sistema ILPF no período de chuva e seca.

\section{MATERIAL E MÉTODOS}

O trabalho foi conduzido na fazenda experimental da Universidade Estadual de Goiás, Campus Ipameri, geograficamente localizada a 1743’07" de latitude sul e longitude oeste de $48^{\circ} 08^{\circ} 42^{\prime \prime}$, altitude média de $781 \mathrm{~m}$. O clima da região, segundo a classificação de Köppen, é tropical semiúmido (Aw), constando temperatura média de $21,9^{\circ} \mathrm{C}$, umidade relativa do ar entre $58 \%$ a $81 \%$ e, aproximadamente, $1.447 \mathrm{~mm}$ de precipitação anual, com uma maior concentração de chuvas nos meses de outubro a março. O solo da área onde foram feitas as amostragens é classificado como Latossolo Vermelho-Amarelo distrófico inserido no bioma cerrado.

A área de estudo possui renques do híbrido de Eucalyptus grandis"GG100" dispostos em fileiras duplas ( $3 \mathrm{~m} \times 2 \mathrm{~m} \times 17 \mathrm{~m}$ ), com 65 meses de idade, na qual foram escolhidos dois renques com a dimensão de 21 × 90 m em uma malha amostral com 
grade regular composta por células de $3 \times 7,5 \mathrm{~m}$, totalizando 52 pontos de amostragem na camada de 0,00-0,10 m, sendo todos os pontos georreferenciados.

Na estação chuvosa, a soja foi semeada, mecanicamente, no dia 21 de novembro de 2015. Utilizou-se a cultivar Monsoy 7739 IPRO, ciclo médio, com espaçamento de 0,40 m na entrelinha, e densidade de 12 plantas por metro linear. As sementes receberam tratamento com fungicidas, na dose de $100 \mathrm{ml} 100 \mathrm{~kg}^{-1}$, e o inoculante, na dose $1 \mathrm{~g} \mathrm{~kg}^{-1}$, de semente. A adubação química básica realizada no sulco de semeadura foi calculada de acordo com as características químicas do solo e levando em consideração as recomendações de Alvarez et al. (1999), sendo constituída do formulado NPK 02-28-18, na dose de $300 \mathrm{~kg} \mathrm{ha}^{-1}$. Para o controle de doenças, foi utilizado 0,3 L ha-1 de Azoxistrobina + Ciproconazol no florescimento, e, para controle de pragas, foram utilizados óleo mineral e Imidacloprid + Beta-Ciflutrina (0,5 e 0,75 L $\mathrm{h}^{-1}$, respectivamente) conforme avaliação periódica por meio da batida de pano. Após a colheita da soja, a área foi deixada em pousio durante o período seco até o mês de agosto de 2016.

As coletas do solo foram realizadas com o auxílio de um trado tipo holandês na camada superficial (0,00-0,10 m), no dia 21 de janeiro de 2016, na época chuvosa durante o florescimento da soja e no dia 15 julho de 2016, na época seca, quando a área estava em pousio. As amostras coletadas foram mantidas em caixas de isopor e resfriadas durante o transporte até o laboratório de solos da Universidade Estadual de Goiás, Campus de Ipameri, onde foram homogeneizadas, passadas por uma peneira de malha $4 \mathrm{~mm}$, sendo uma parte retirada para análises de umidade e o restante armazenado em geladeira a uma temperatura de $7 \pm 3^{\circ} \mathrm{C}$ até o dia seguinte, iniciandose as análises microbiológicas.

O CBM foi obtido pelo método da irradiação-extração (MENDONÇA; MATOS, 2005). Essa técnica utiliza energia eletromagnética (micro-ondas), através da transferência de energia e temperatura, para causar um rompimento celular com liberação dos compostos intracelulares. A energia necessária para promover a lise 
bacteriana é de $800 \mathrm{~J} \mathrm{~s}^{-1} \mathrm{~g}^{-1}$, solo em base seca, antes da realização da extração. A calibração do aparelho de micro-ondas foi realizada utilizando um volume conhecido de água e, em seguida, foi preestabelecido o tempo de irradiação para a elevação da temperatura no interior do micro-ondas. Por fim, a extração foi realizada com sulfato de potássio 0,5 mol L-1; a oxidação, com dicromato de potássio 0,066 mol L-1; e a titulação, com sulfato ferroso amoniacal 0,033 mol L-1 (ISLAM; WEIL, 1998).

A avaliação da respiração microbiana $\left(\mathrm{C}-\mathrm{CO}_{2}\right)$ foi realizada juntamente com a avaliação do CBM, sendo estimada pela quantidade de $\mathrm{CO}_{2}$ liberado do solo não fumigado, durante sete dias de incubação. Os dados da respiração microbiana foram expressos em mg C- $\mathrm{CO}_{2} \mathrm{~kg}$ de solo-1. $\mathrm{O} \mathrm{qCO}_{2}$ foi calculado pela razão entre $\mathrm{C}-\mathrm{CO}_{2}$ liberado e o CBM (ANDERSON; DOMSCH, 1993), sendo expresso em (mg C-CO $\mathrm{CO}_{2}$ C-BM-1 $\left.\mathrm{kg}^{-1} \mathrm{~h}^{-1}\right) \cdot 10^{3}$, conforme as Equações (1) e (2) a seguir:

$$
\begin{aligned}
& q \mathrm{CO} 2=\mathrm{RM} / \mathrm{CBM} \\
& \mathrm{C}-\mathrm{CO} 2 \text { liberado }=\mathrm{TRM} / \mathrm{h}
\end{aligned}
$$

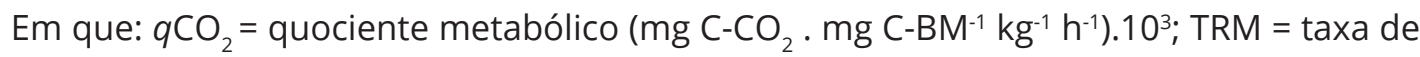
respiração microbiana ( $\mathrm{mg} \mathrm{C}-\mathrm{CO}_{2} . \mathrm{kg}$ de solo-1); $\mathrm{C}-\mathrm{CO}_{2}$ liberado = atividade microbiana ( $m g$ C- $-\mathrm{CO}_{2} \cdot k g$ de solo-1 $\mathrm{h}^{-1}$ ); $\mathrm{H}=$ horas de incubação para a determinação da respiração microbiana; $\mathrm{CBM}=$ carbono da biomassa microbiana (mg C-BM kg-1 de solo seco).

Para a determinação da umidade gravimétrica do solo (UG), foi usado o método termogravimétrico, conforme Embrapa (2009), que consiste em pesar a massa de solo úmido e, em seguida, secá-lo em estufa a $105-110^{\circ} \mathrm{C}$ por 24 horas, e, após esses passos, determinar sua massa seca, conforme Equação (3):

$$
\theta=M S U-M S S / M S S
$$

Em que: $U G$ = Umidade Gravimétrica $\left(\mathrm{g} \mathrm{g}^{-1}\right) ; \mathrm{MSU}=$ Massa de Solo Úmida (g); $\mathrm{MSS}=$ Massa de Solo Seco (g). 
Para cada atributo analisado, foi realizada a análise descritiva auxiliada pela estatística clássica. O software SAS (SCHLOTZHAVER; LITTEL, 1997) foi utilizado para calcular a média, mediana, moda, valores mínimo e máximo, desvio-padrão, coeficiente de variação, curtose e assimetria. Foram identificados os outliers (dados discrepantes), conforme identificação do gráfico de ramos e folhas, executando sua substituição pelo valor médio dos circunvizinhos. Também foi efetuada a análise da distribuição de frequência por meio do teste de Shapiro e Wilk (1965), com 1\% probabilidade de erro.

O ajuste geoespacial foi executado com o auxílio do programa $\mathrm{GS}^{+} 7.0$ (ROBERTSON, 1998). A análise inicial dos dados comprovou que, para alguns atributos, a tendência foi retirada.Utilizando o método do refinamento da mediana desses atributos, conforme proposto por Silva et al. (2003):

$$
V=V O-(M L+M C)+M G
$$

Em que: NV representou o novo valor residual do atributo do qual foi retirada a tendência; VO o valor original do atributo do qual foi retirada a tendência; ML e MC representam, respectivamente, os valores da mediana da linha e da coluna nas quais estava o atributo; MG representou a mediana geral dos atributos contidos na malha amostral.

Assim, calculou-se novamente o semivariograma com os resíduos obtidos desse procedimento. O ajuste do semivariograma efetuado por meio da validação cruzada, de acordo com Robertson (1998), permitiu determinar os parâmetros de ajuste do semivariograma experimental: efeito pepita $\left(C_{0}\right)$, variância estrutural $\left(C_{1}\right)$ e alcance $(a)$. O grau de dependência espacial (GD), também estudado por Montanari et al. (2010), onde valores $\leq 25 \%$ indicam grau de dependência espacial fraco; de 25\% - 75\% indicam grau de dependência espacial moderado; e > 75\% indicam grau de dependência espacial forte entre amostras - Equação (5):

$$
G D=\left[\left(\frac{C_{1}}{C_{0}+C_{1}}\right)\right] * 100
$$

O método de krigagem foi utilizado para estimar valores nos locais não 
amostrados por ser um estimador linear não enviesado. Após determinados os valores para os locais não amostrados, com a ajuda da técnica de krigagem, construíram-se os mapas de isolinhas utilizando-se o programa GS+(Robertson 1998), que emprega os mesmos valores estimados por meio da técnica de krigagem para determinação e localização das isolinhas. Dessa maneira, os mapas representam linhas bem definidas e embasadas em um algoritmo de regressão linear, conforme descrito por Carvalho e Assad (2002) e Siqueira et al. (2008).

\section{RESULTADOS E DISCUSSÃO}

Na Tabela 1, observam-se os valores das medidas descritivas dos atributos microbiológicos do solo sob ILPF em duas estações, chuvosa (soja) e seca (pousio). A análise de normalidade na estação chuvosa apresentou distribuição de frequência normal ( $p$-valor $=0,250$ ) apenas para o atributo UG. Já na estação seca, os atributos que apresentaram distribuição de frequência normal foram C- $\mathrm{CO}_{2}$ (p-valor $\left.=0,7205\right)$ e UG (p-valor $=0,369)$. A normalidade não é uma exigência da geoestatística, sendo conveniente que o gráfico de distribuição de frequência não apresente caudas muitos alongadas, podendo comprometer as análises (CRESSIE, 1991).

Ao avaliar a variabilidade dos atributos microbiológicos, foi utilizado o coeficiente de variação (CV). Segundo Landim (2003), o CV fornece uma medida relativa da precisão do experimento, sendo bastante útil na dispersão dos dados. Os valores de CV na estação chuvosa foram menores (variando entre 8,4 e 39,2) quando comparados com a estação seca, mas apresentaram distribuição de frequência normal apenas para UG. Mesmo apresentando os maiores valores de CV (variando entre 109,3 e 7,1), quando comparados com a estação chuvosa, os atributos C- $\mathrm{CO}_{2}$ e UG na estação seca apresentaram distribuição normal.

Em relação à assimetria, na estação chuvosa, os valores variaram entre -0,2 e 1,1; sendo que, para os atributos $C B M$ e UG, essa tende à esquerda, já para $q \mathrm{CO}_{2}$ e $\mathrm{C}-\mathrm{CO}_{2}$ a assimetria tende à direita. Na estação seca, todos os atributos estudados 
tiveram assimetria tendendo para a direita e os valores variaram entre 0,3 e 1,9. Os coeficientes de curtose ficaram entre -0,5 e 3,8 para a estação chuvosa. Já na estação seca, por sua vez, esses valores variaram entre -0,2 e 2,6.

Tabela 1 - Análise descritiva da atividade microbiana e umidade gravimétrica de um solo sob integração-lavoura-pecuária-floresta

\begin{tabular}{|c|c|c|c|c|c|c|c|c|c|c|}
\hline \multirow{3}{*}{ Atributo(a) } & \multicolumn{10}{|c|}{ Medidas estatísticas descritivas } \\
\hline & \multirow{2}{*}{ Média } & \multirow{2}{*}{ Mediana } & \multicolumn{2}{|c|}{ Valor } & \multirow{2}{*}{$\begin{array}{l}\text { Desvio } \\
\text { Padrão }\end{array}$} & \multicolumn{3}{|c|}{ Coeficiente } & \multicolumn{2}{|c|}{$\begin{array}{c}\text { Probabilidade } \\
\text { do teste }^{(b)}\end{array}$} \\
\hline & & & Mínimo & Máximo & & $\begin{array}{c}\text { Variação } \\
\text { (\%) }\end{array}$ & Curtose & Assimetria & $\operatorname{Pr}<w$ & DF \\
\hline \multicolumn{11}{|c|}{ Estação chuvosa (Soja) } \\
\hline CBM & 365,4 & 375,5 & 101,6 & 561,8 & 106,1 & 29,0 & $-0,5$ & $-0,2$ & 0,0092 & IN \\
\hline $\mathrm{C}-\mathrm{CO}_{2}$ & 1,5 & 1,5 & 0,8 & 2,2 & 0,3 & 18,2 & 3,8 & 0,2 & 0,0001 & IN \\
\hline$q \mathrm{CO}_{2}$ & 4,5 & 4,0 & 1,2 & 9,1 & 1,8 & 39,2 & 0,3 & 1,1 & 0,0001 & IN \\
\hline UG & 0,21 & 0,21 & 0,2 & 0,2 & 0,02 & 8,4 & 0,9 & $-0,5$ & 0,2500 & NO \\
\hline \multicolumn{11}{|c|}{ Estação seca (Pousio) } \\
\hline CBM & 217,6 & 188,2 & 18,8 & 752,8 & 180,5 & 82,9 & 0,8 & 1,1 & 0,0001 & IN \\
\hline $\mathrm{C}-\mathrm{CO}_{2}$ & 1,4 & 1,4 & 0,7 & 2,3 & 0,4 & 25,7 & $-0,2$ & 0,3 & 0,7205 & NO \\
\hline$q \mathrm{CO}_{2}$ & 15,1 & 8,4 & 1,2 & 63,8 & 16,5 & 109,3 & 2,6 & 1,9 & 0,0001 & IN \\
\hline UG & 0,14 & 0,14 & 0,12 & 0,17 & 0,01 & 7,1 & 1,8 & 0,4 & 0,3696 & NO \\
\hline
\end{tabular}

Fonte: Autores (2016)

Em que: (a) $\mathrm{CBM}=$ carbono da biomassa microbiana ( $\mathrm{mg} \mathrm{C}^{-B M ~ k g-1}$ de solo); $\mathrm{CCO}_{2}=$ carbono da atividade microbiana (mg C-BM kg-1 $\left.\mathrm{h}^{-1}\right) ; q \mathrm{CO}_{2}=$ quociente microbiano ((mg C-BM.kg-1 $\left.\left.\mathrm{h}^{-1}\right) 10^{-3}\right)$; Ug = umidade gravimétrica $\left(\mathrm{g} \mathrm{g}^{-1}\right)$; DF = distribuição de frequência, sendo NO e IN respectivamente do tipo normal e indeterminada.

Dessa forma, a distribuição de frequência do tipo normal obtida para os referidos atributos, assim como as magnitudes dos coeficientes de assimetria e de curtose, ficou, no geral, em concordância com dados análogos observados por Corrêa et al. (2015). Nesse estudo, ao trabalharem com sistema silvipastoril em uma malha amostral com 72 pontos amostrais correlacionados com atributos de um Neossolo Quartzarênico em Mato Grosso do Sul, encontram-se valores de assimetria variando entre -0,689 a 0,839 e curtose entre -0,720 a 1,134. Montanari et al. (2015), estudando a variabilidade espacial da produtividade de sorgo e de atributos do solo na região de 
transição Cerrado-Pantanal-MS, em uma grade amostral com 51 pontos amostrais em um Planossolo, verificaram valores de assimetria variando de -0,553 a 0,926 e curtose de $-0,471$ a 2,612.

Quando uma variável estatística qualquer possuir distribuição de frequência do tipo normal, a medida de tendência central mais adequada para representá-la deve ser a média; em contrapartida, será representada pela mediana, ou pela média geométrica, caso seja do tipo lognormal (DALCHIAVON et al. 2017). Na estação chuvosa, para o atributo UG, a média foi de 0,21; a mediana para $\mathrm{CBM}, \mathrm{C}-\mathrm{CO}_{2}$ e $q \mathrm{CO}_{2}$ foram, respectivamente, 375,5; 1,5 e 4,0. Na estação seca, a média para C-CO ${ }_{2}$ e UG foi 217,6 e 0,14, respectivamente; já a mediana para $\mathrm{CBM}_{\text {e }} q \mathrm{CO}_{2}$ foi de 188,2 e 8,4.

Por meio da matriz de correlação (Tabela 2), é possível observar que, tanto na estação chuvosa como na seca, os atributos $q \mathrm{CO}_{2}$ e CBM apresentam correlação inversamente proporcional, enquanto $q \mathrm{CO}_{2}$ e C-CO apresentaram correlação positiva na estação chuvosa, ou seja, à medida que CBM aumenta, o qCO $\mathrm{CO}_{2}$ reduz, evidenciando a melhor eficiência da microfauna no uso do substrato.

Tabela 2 - Matriz de correlação linear simples entre os atributos microbiológicos e umidade do solo

\begin{tabular}{lccc}
\hline \multirow{2}{*}{ Atributos $^{(\mathbf{a})}$} & \multicolumn{3}{c}{ Coeficiente de correlação $^{\text {(b) }}$} \\
\cline { 2 - 4 } & $\mathbf{C B M}$ & $\mathbf{C}-\mathrm{CO}_{2}$ & $\mathbf{q C O}_{\mathbf{2}}$ \\
\hline $\mathrm{C}-\mathrm{CO}_{2}$ & 0,019 & Estação chuvosa (Soja) & - \\
$q \mathrm{CO}_{2}$ & $-0,691^{* *}$ & - & - \\
$\mathrm{UG}$ & $-0,164$ & $0,485^{* *}$ & 0,147 \\
\hline & & 0,083 & - \\
\hline $\mathrm{C}-\mathrm{CO}_{2}$ & 0,104 & Estação seca (Pousio) & - \\
$q \mathrm{CO}_{2}$ & $-0,633^{* *}$ & - & $-0,211$ \\
$\mathrm{UG}$ & 0,207 & 0,184 & \\
\hline
\end{tabular}

Fonte: Autores (2016)

Em que: (a) $\mathrm{CBM}=$ carbono da biomassa microbiana ( $\mathrm{mg} \mathrm{C}-\mathrm{BM} \mathrm{kg}{ }^{-1}$ de solo); $\mathrm{C}^{-\mathrm{CO}_{2}}=$ carbono da atividade microbiana (mg C-BM kg-1 $\left.\mathrm{h}^{-1}\right) ; q \mathrm{CO}_{2}=$ quociente microbiano (( $\left.\mathrm{mg} \mathrm{C}^{-B M ~ k g}{ }^{-1} \mathrm{~h}^{-1}\right)$ 10-3); UG = umidade gravimétrica $\left(\mathrm{g} \mathrm{g}^{-1}\right)$; DF = distribuição de frequência, sendo $\mathrm{NO}$ e IN, respectivamente, do tipo normal e indeterminada; ${ }^{(b) *}$ Significativo a $5 \%,{ }^{* *}$ Significativo a $1 \%$. 
Em contrapartida, à medida que o $\mathrm{C}-\mathrm{CO}_{2}$ aumenta, o quociente metabólico também aumenta, sugerindo que, na estação chuvosa, o plantio de soja provavelmente incorpora carbono orgânico no solo, o que proporciona um incremento maior na atividade metabólica dos microrganismos do que incorporação de carbono nos tecidos microbianos. No entanto, Carbonell-Bojollo et al. (2012) relatam que a emissão de $\mathrm{CO}_{2}$ nem sempre está correlacionada com o carbono orgânico do solo e o aumento da emissão de $\mathrm{CO}_{2}$ está associado ao estoque de carbono do solo, que é complexo, podendo envolver feedbacks positivos e negativos, necessitando de mais estudos entre o fluxo de $\mathrm{CO}_{2}$ e a dinâmica do carbono do solo (SONG et al., 2013). No estudo realizado por Xu e Qi (2001), a emissão de $\mathrm{CO}_{2}$ apresentou correlação significativa e positiva com a biomassa microbiana, a biomassa das raízes, o nitrogênio, a matéria orgânica e o teor de magnésio.

As correlações entre as medidas de $\mathrm{qCO}_{2}$ e CBM foram significativas ao nível de $1 \%$ de probabilidade, e variaram de -0,633 a -0,691, entre as estações chuvosa e seca, respectivamente. Observou-se correlação significativa a 1\% entre as medidas $q \mathrm{CO}_{2}$ e C- $\mathrm{CO}_{2}$ na estação chuvosa (Tabela 2).

Colman etal.(2013), avaliando a qualidade do solo em diferentes sistemas de ILPF, observaram que a respiração microbiana $\left(C-\mathrm{CO}_{2}\right)$ e o CBM foram influenciados pelos sistemas de manejo avaliados. O carbono da biomassa microbiana é positivamente relacionado com a liberação de $\mathrm{CO}_{2}$, ou seja, a atividade microbiana está associada à quantidade de microrganismos (CATTELAN; VIDOR, 1990).

Em relação ao CBM, Alvarenga e Noce (2005) afirmaram que o acúmulo de palhada e raízes proporcionado pela pastagem tende a aumentar a matéria orgânica do solo, e, consequentemente, aumentar a quantidade de carbono disponível para os microrganismos. Essa elevada taxa é desejável, uma vez que a decomposição dos resíduos orgânicos irá disponibilizar nutrientes às plantas. Segundo Lourente et al. (2011), a biomassa microbiana foi mais eficiente durante o verão, ou seja, houve menos perda de $\mathrm{CO}_{2}$ por unidade de biomassa e redução nos valores de $q \mathrm{CO}_{2}$, assim como observado neste trabalho. 
Tabela 3 - Análise geoestatística da atividade microbiana e umidade em um solo sob interação-lavoura-pecuária-floresta

\begin{tabular}{|c|c|c|c|c|c|c|c|c|c|c|c|}
\hline \multirow{3}{*}{ Atributo $^{\mathrm{s}(\mathrm{a})}$} & \multicolumn{11}{|c|}{ Parâmetros } \\
\hline & \multirow[t]{2}{*}{ Modelo $^{(b)}$} & \multirow{2}{*}{$\begin{array}{l}\text { Efeito } \\
\text { pepita } \\
\left(C_{0}\right)\end{array}$} & \multirow{2}{*}{$\begin{array}{l}\text { Patamar } \\
\left(\mathrm{C}_{0}+\mathrm{C}\right)\end{array}$} & \multirow{2}{*}{$\begin{array}{l}\text { Alcance } \\
\left(A_{0}\right)(m)\end{array}$} & \multirow[t]{2}{*}{$\mathbf{r}^{2}$} & \multirow[t]{2}{*}{$S Q R^{(c)}$} & \multicolumn{2}{|c|}{$A D E^{(d)}$} & \multicolumn{3}{|c|}{$\begin{array}{c}\text { Validação } \\
\text { cruzada }\end{array}$} \\
\hline & & & & & & & $\%$ & Classe $^{*}$ & A & b & $r$ \\
\hline \multicolumn{12}{|c|}{ Seca (Pousio) } \\
\hline CBM & esf (35) & $1,3 \times 10^{-4}$ & $2,802 \times 10^{4}$ & 20,0 & 0,589 & $1,0 \times 10^{4}$ & 50,9 & $\mathrm{M}$ & 62,9 & 0,711 & 0,12 \\
\hline $\mathrm{C}-\mathrm{CO}_{2}$ & esf (34) & $4,9 \times 10^{-2}$ & $1,396 \times 10^{1}$ & 13,5 & 0,518 & $2,6 \times 10^{-3}$ & 63,9 & $A L$ & 0,67 & 0,538 & 0,05 \\
\hline$q \mathrm{CO}_{2}$ & esf (37) & $6,4 \times 10^{1}$ & $2,792 \times 10^{2}$ & 26,6 & 0,429 & $4,9 \times 10^{5}$ & 77,0 & $\mathrm{AL}$ & 5,43 & 0,593 & 0,096 \\
\hline UG & esf (37) & $4,6 \times 10^{-5}$ & $9,800 \times 10^{-5}$ & 14,9 & 0,340 & $2,5 \times 10^{-9}$ & 53,1 & M & 0,04 & 0,068 & 0,16 \\
\hline \multicolumn{12}{|c|}{ Chuva (Soja) } \\
\hline CBM & $\exp (35)$ & $7,2 \times 10^{1}$ & $9,300 \times 10^{3}$ & 7,5 & 0,258 & $2,1 \times 10^{7}$ & 92,4 & MA & 158,7 & 0,553 & 0,032 \\
\hline $\mathrm{C}-\mathrm{CO}_{2}$ & - & $7,5 \times 10^{-2}$ & - & - & - & - & - & - & - & - & - \\
\hline$q \mathrm{CO}_{2}$ & $\exp (37)$ & $5,0 \times 10^{-1}$ & $3,319 \times 10^{2}$ & 8,7 & 0,625 & $5,110^{1}$ & 84,7 & MA & 2,910 & 0,371 & 0,015 \\
\hline UG & $\exp (35)$ & $1,8 \times 10^{-5}$ & $2,900 \times 10^{-4}$ & 7,5 & 0,134 & $3,6 \times 10^{-8}$ & 94,1 & MA & 0,040 & 0,802 & 0,114 \\
\hline \multicolumn{12}{|c|}{ Y (h) cruzado - Seca } \\
\hline$q \mathrm{CO}_{2}=\mathrm{f}(\mathrm{CBM})$ & gau (37) & $-4,0 \times 10^{2}$ & $-2,055 \times 10^{3}$ & 15,6 & 0,714 & $8,0 \times 10^{6}$ & 77,8 & $\mathrm{AL}$ & 2,180 & 0,826 & 0,313 \\
\hline \multicolumn{12}{|c|}{ Y (h) cruzado - Chuva } \\
\hline$q \mathrm{CO}_{2}=\mathrm{f}(\mathrm{CBM})$ & esf (34) & $2,3 \times 10^{7}$ & $1,786 \times 10^{8}$ & 11,3 & 0,265 & $2,2 \times 10^{4}$ & 87,0 & MA & 0,610 & 0,882 & 0,184 \\
\hline
\end{tabular}

Fonte: Autores (2016)

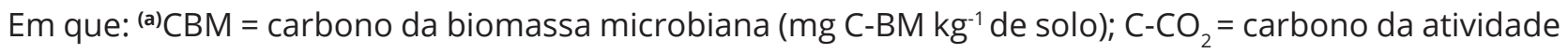
microbiana (mg C-BM kg-1 $\left.\mathrm{h}^{-1}\right) ; q \mathrm{CO}_{2}=$ quociente microbiano ((mg C-BM kg-1 $\left.\left.\mathrm{h}^{-1}\right) 10^{-3}\right)$; UG = umidade gravimétrica $\left(\mathrm{g} \mathrm{g}^{-1}\right) ;{ }^{(b)} \mathrm{ADE}=\mathrm{M}=$ média; $\mathrm{A}=$ alta; $\mathrm{MA}=$ muito alta.

No período chuvoso, as variáveis analisadas apresentaram maior dependência espacial do que no período seco, bem como menores valores de alcance, corroborados pela umidade gravimétrica da área. A umidade e a temperatura do solo são os fatores que mais influenciam a emissão de $\mathrm{CO}_{2}$, sendo que a umidade do solo nem sempre apresenta os mesmos padrões de variabilidade espacial e temporal (LOURENTE et al., 2011). No geral, a umidade do solo é negativamente correlacionada com a emissão de $\mathrm{CO}_{2}$ em estudo da variabilidade espacial e positivamente em variabilidade temporal (XU; QI, 2001; EPRON et al., 2006; KOSUGI et al., 2007; LA SCALA et al., 2010).

Na comparação inicial do mapa de krigagem simples, período seco, os atributos $\mathrm{CBM}, q \mathrm{CO}_{2}, \mathrm{C}-\mathrm{CO}_{2}$ e UG apresentaram elevada semelhança espacial entre si, confirmando a importância da umidade para esses atributos quando em pousio. Dessa 
forma, nas figuras $2 \mathrm{~b}, \mathrm{~d}, \mathrm{f}, \mathrm{g}$, constatou-se que, nos sítios onde ocorreram os maiores valores de $\mathrm{CBM}$ e UG, houve menores valores de $\mathrm{C}-\mathrm{CO}_{2}$ e $q \mathrm{CO}_{2}$, consequentemente. Entretanto, para o período chuvoso, esse fato não ocorreu de forma evidente, apenas em pontos específicos, como a região centro-oeste dos mapas.

Figura 1 - Mapas de krigagem dos atributos

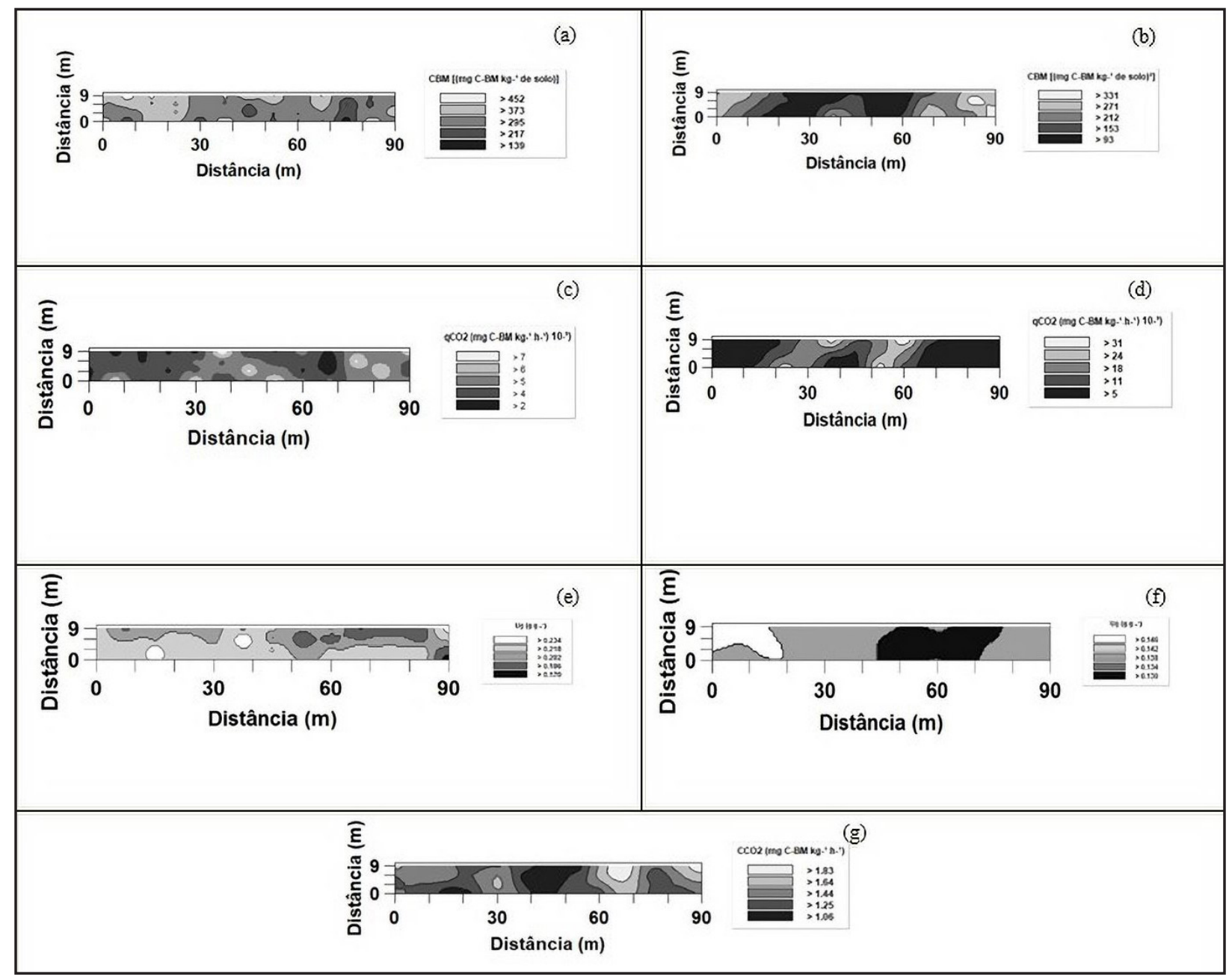

Fonte: Autores (2016)

Em que: $\left(\mathrm{CBM}=\right.$ Carbono da biomassa microbiana (mg C-BM kg-1 de solo); $\mathrm{C}^{-} \mathrm{CO}_{2}=$ Carbono da atividade microbiana ( $\left.\mathrm{mg} \mathrm{C}^{-B M ~ k g-1} \mathrm{~h}^{-1}\right) ; q \mathrm{CO}_{2}=$ Quociente microbiano ((mg C-BM g-1 $\left.\left.\mathrm{h}^{-1}\right) 10^{-3}\right) ; \mathrm{UG}=$ Umidade gravimétrica ( $\mathrm{g} \mathrm{g}^{-1}$ ); letras: a, c, e, análises período chuvoso, b, d, f, g, período seca.

Nas figuras 3a e 3b, estão contidos os semivariogramas cruzados e, nas figuras $3 c$ e 3d, estão contidos os mapas de co-krigagem entre os atributos que apresentaram dependência espacial entre si. Atestando a inter-relação espacial CBM, foi confirmado 
que apenas a $q \mathrm{CO}_{2}$ resultou co-krigagem, evidenciando que $71,4 \%$ no período chuvoso e $26,5 \%$ no período seco da variabilidade espacial do CBM no sistema ILPF foram explicadas pela variabilidade espacial da $q \mathrm{CO}_{2}$.

Figura 2 - Mapas de co-krigagem do atributo $q \mathrm{CO}_{2}=$ Quociente microbiano (mg C-BM. $\left.\left.\mathrm{kg}^{-1} \mathrm{~h}^{-1}\right) 10^{-3}\right)$. (a) e (c) - análises do período chuvoso; (b) e (d) - período seco

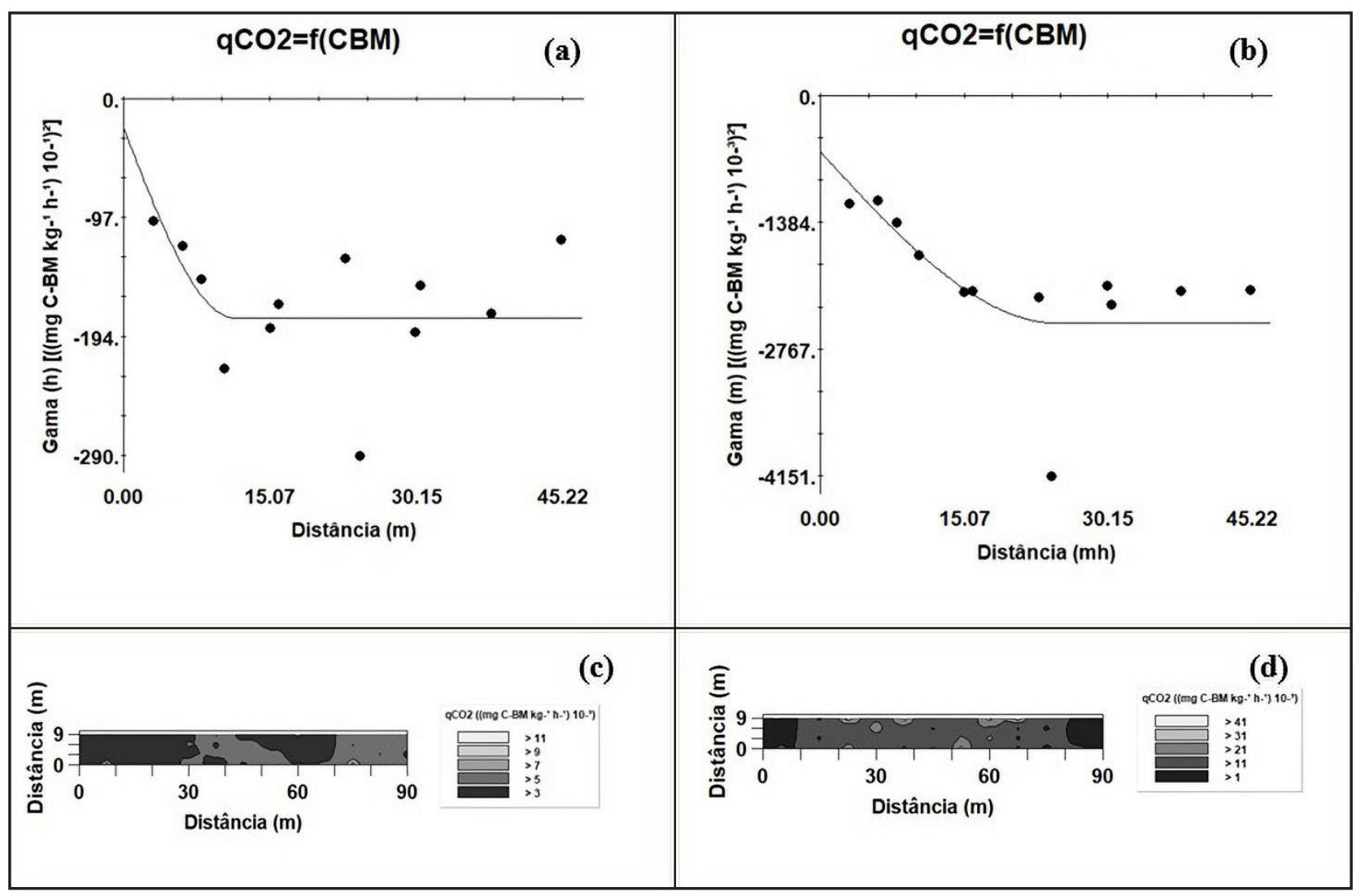

Fonte: Autores (2016)

\section{CONCLUSÕES}

Os atributos da atividade microbiológica do solo foram bons indicadores de zonas de manejo específico para qualidade do solo.

O $q \mathrm{CO}_{2}$ foi a variável microbiológica que melhor representou, linear e espacialmente, a variabilidade do solo sob o sistema ILPF, refletindo as zonas de maior eficiência do uso do substrato pelos organismos do solo. 
Os atributos apresentaram maior dependência espacial no período chuvoso.

No período chuvoso, ocorreu menor variabilidade dos dados em relação ao período seco.

$\mathrm{O} q \mathrm{CO}_{2}$ apresentou relação direta $\mathrm{com} \mathrm{C}-\mathrm{CO}_{2}$ no período chuvoso, enquanto CBM apresentou relação inversamente proporcional, tanto no período chuvoso como no seco.

\section{REFERÊNCIAS}

ALCÂNTARA NetO, F.; LeITE, L. F. C.; ARNHOld, E.; MACIEL, G. A.; CARNEIRO, R. F. V. Compartimentos de carbono em Latossolo Vermelho sob cultivo de eucalipto e fitofisionomias de cerrado. Revista Brasileira de Ciência do Solo, Viçosa, v. 35, n. 3, p. 849-856, 2011.

ALVARENGA, R. C.; PORFÍRIO-DA-SILVA, V.; GONTIJO NETO, M. M.; VIANA, M. C. M.; VILELA, L. Sistema Integração Lavoura-Pecuária-Floresta: condicionamento do solo e intensificação da produção de lavouras. Informe Agropecuário, Belo Horizonte, v. 31, n. 257, p. 59-67, jul./ago. 2010.

ALVARENGA, R. C.; NOCE, M. A. Integração lavoura-pecuária. Sete Lagoas: Embrapa Milho e Sorgo, 2005. 16 p. Documentos, 47.

ALVAREZ, V. V. H.; NOVAIS, R. F.; BARROS, N. F.; CANTARUTTI, R. B.; LOPES, A. S. Interpretação dos resultados das análises de solos. In: RIBEIRO, A. C.; GUIMARAES, P. T. G.; ALVAREZ, V. V. H. (Ed.). Recomendação para o uso de corretivos e fertilizantes em Minas Gerais: $5^{\text {a }}$ Aproximação. Viçosa: Comissão de Fertilidade do Solo do Estado de Minas Gerais, 1999. p. 25-32.

ANDERSON, T. H.; DOMSCH, K. H. The metabolic quotient for $\mathrm{CO}_{2}\left(\mathrm{qCO}_{2}\right)$ as a specific activity parameter to assess the effects of environmental conditions, such as $\mathrm{pH}$ on the microbial biomass of forest soils. Soil Biology and Biochemistry, Amsterdam, v. 25, n. 3, p. 393-395, 1993.

CARBONELL, R.; REPULLO, M. A.; RODRIGUEZ-LIZANA, A.; ORDONEZ-FERNANDEZ, R. Influence of soil and climate conditions on $\mathrm{CO}_{2}$ emissions from agricultural soils. Water, Air and Soil Pollution, v. 223, n. 6, p. 3425-3435, 2012.

CARVALHO, J. R. P.; ASSAD, E. D. Comparação de interpoladores espaciais univariados para precipitação pluvial anual no Estado de São Paulo. Campinas: Embrapa Informática Agropecuária, 2002. (Embrapa Informática Agropecuária. Comunicado Técnico, 33).

CATTELAN, A. J.; VIDOR, C. Flutuações na biomassa, atividade e população microbiana do solo em função de variações ambientais. Revista Brasileira de Ciência do Solo, Viçosa, v. 14, n. 2, p. 133-142, 1990. 
COLMAN, B. A.; SALTON, J. C.; MERCANTE, F. M. Indicadores microbiológicos para avaliação da qualidade do solo em diferentes sistemas de integração lavoura-pecuária-floresta. In: CONGRESSO BRASILEIRO DE CIÊNCIA DO SOLO, 34., 2013, Florianópolis. Anais [...]. Florianópolis: Sociedade Brasileira de Ciência do Solo, 2013. Disponível em: https://www.alice. cnptia.embrapa.br/bitstream/doc/966925/1/CBCSCOLMANINDICADORES.pdf. Acesso em: 31 jan. 2018.

CORRÊA, A. R.; MONTANARI, R.; LAURA, V. A.; MELOTTO, A. M.; SILVA, E. N. S.; PELLIN, D. M. P.; PELLIN, D. M. P.; SANTOS, A. S. Aspects of the silvopastoral system correlated with properties of a Typic Quartzipsamment (entisol) in Mato Grosso do Sul, Brasil. Revista Brasileira de Ciência do Solo, Viçosa, v. 39, n. 2, p. 438-447, 2015.

CRESSIE, N. A. C. Statistics for spatial data. New York: John Wiley \& Sons, 1991. 900 p.

DALCHIAVON, F. C.; CARVALHO, M. P. Correlação linear e espacial dos componentes de produção e produtividade da soja. Semina: Ciências Agrárias, Londrina, v. 33, n. 2, p. 541552, abr. 2012.

DALCHIAVON, F. C.; MONTANARI, R.; ANDREOTTI, M. Production and quality of Urochloa decumbens (stapf) r.d. webster forage co-related to the physical and chemical properties of the soil. Revista Ceres, Viçosa, v. 64, n. 3, p. 315-326, 2017.

EMPRESA BRASILEIRA DE PESQUISA AGROPECUÁRIA. EMBRAPA. Manual de métodos de análise do solo. Brasília: Embrapa Produção de Informação, 2009. 212 p.

EMPRESA BRASILEIRA DE PESQUISA AGROPECUÁRIA. EMBRAPA. Manual de métodos de análises de solo. 2. ed. Rio de Janeiro: Ministério da Agricultura e do Abastecimento, 1997. 212 p.

EPRON, D.; NOUVELLON, Y.; ROUPSARD, O.; MOUVONDY, W.; MABIALA, A.; SAINT-ANDRÉ, L.; JOFFRE, R.; JOURDAN, C.; BONNEFOND, J. M.; BERBIEGER, P.; HAMEL, O. Spatial and temporal variations of soil respiration in a Eucalyptus plantation in Congo. Forest, Ecology and Management, Amsterdam, v. 202, p. 149-160, 2004.

EPRON, D.; BOSC, A.; BONAL, D.; FREYCON, V. Spatial variation of soil respiration across a topographic gradient in a tropical rain forest in French Guiana. Journal of Tropical Ecology, Cambridge, v. 22, n. 5, p. 565-574, 2006.

GAZOLA, R. N.; LOVERA, L. H.; CELESTRINO, T. S.; DINALLI, R. P.; MONTANARI, R.; QUEIROZ, H. A. Variabilidade espacial das concentrações de nutrientes foliares da soja correlacionadas com atributos químicos de um Latossolo Vermelho distroférrico. Revista Ceres, Viçosa, v. 64, n. 4, p. 441-449, 2017.

GUANGMING, L.; ZHANG, X.; XIUPING, W.; SHAO, H. Soil enzymes as indicators of saline soil fertility under various soil amendments. Agriculture, Ecosystems \& Environment, Amsterdam, v. 237, p. 274-279, 2017.

INSAM, H.; MITCHELL, C. C.; DORMAAR, J. F. Relationship of soil microbial biomass and activity with fertilization practice and crop yield of three ultisols. Soil Biology \& Biochemistry, Oxford, v. 23, n.5, p.459-464, 1991. 
ISLAM, K. R.; WEIL, R. R. Microwave irradiation of soil for routine measurement of microbial biomass carbon. Biology and Fertility of Soils, Berlin, v. 27, n. 4, p. 408-416, 1998.

KOSUGI, Y.; ITOH, M.; NOGUCHI, S.; MITANI, T. Spatial and temporal variation in soil respiration in a Southeast Asian tropical rainforest. Agricultural and Forest Meteorology, Amsterdam, v. 147, p. 35-47, 2007.

LA SCALA JÚNIOR, N.; MENDONÇA, E. S.; SOUZA, J. V.; PANOSSO, A. R.; SIMAS, F. N. B.; SCHAEFER, C. E. G. R. Spatial and temporal variability in soil $\mathrm{CO}_{2}$ e $\mathrm{C}$ emissions and relation to soil temperature at King George Island, maritime Antarctica. National Institute of Polar Research, Tokyo, v. 4, n. 3, p. 479-487, Dec. 2010.

LANDIM, P. M. B. Análise estatística de dados geológicos. 2. ed. São Paulo: Editora UNESP, 2003. 253 p.

LIMA, E. S.; SOUZA, Z. M.; MONTANARI, R.; OLIVEIRA, S. R. M.; LOVERA, L. H.; FARHATE, C. V. V. Classification of the initial development of eucaliptus using data mining techniques. CERNE, Lavras, v. 23, n. 2, p. 201-208, Apr./June, 2017.

LOURENTE, E. R. P.; MERCANTE, F. M.; ALOVISI, A. M. T.; GOMES, C. F.; GASPARINI, A. S.; NUNES, C. M. Atributos microbiológicos, químicos e físicos de solo sob diferentes sistemas de manejo e condições de cerrado. Pesquisa Agropecuária Tropical, Goiânia, v. 41, n. 1, p. 20-28, jan./ mar. 2011.

MAHARJAN, M.; SANAULLAH, M.; RAZAVI, B.; KUZYAKOV, Y. Effect of land use and management practices on microbial biomass and enzyme activities in subtropical top-and sub-soils. Applied Soil Ecology, Amsterdam, v. 113, p. 22-28, 2017.

MENDONÇA, E. S.; MATOS, E. S. Matéria orgânica do solo; métodos de análises. Viçosa, MG: Universidade Federal de Viçosa, 2005. 107 p.

MONTANARI, R; CARVALHO, M. P.; ANDREOTTI, M.; DALCHIAVON, F. C.; LOVERA, L. H.; HONORATO, M. A. O. Aspectos da produtividade do feijão correlacionados com atributos físicos do solo sob elevado nível tecnológico de manejo. Revista Brasileira de Ciência do Solo, Viçosa, v. 34, n. 6, p. 1811-1822, nov./dez. 2010.

MOREIRA, F. M. S.; SIQUEIRA, J. O. Microbiologia e bioquímica do solo. Lavras: Universidade Federal de Lavras, 2006. 626 p.

ROBERTSON, G.P. GS+: Geostatistics for the environmental sciences (version 5.1 for windows). Plainwell: Gamma Design Software, 1998. 152 p.

SCHLOTZHAVER, S. D.; LITTELL, R. C. SAS system for elementary statical analysis. 2. ed. Cary: SAS, 1997. 441 p.

SHAPIRO, S. S.; WILK, M. B. An analysys of vari-ance test for normality: complete samples. Biometrika, London, v. 52, n. 3/4, p. 591-611, 1965. 
SILVA, V. R.; REICHERT, J. M.; STORCK, L.; FEIJÓ, S. Variabilidade espacial das características químicas do solo e produtividade de milho em um Latossolo Vermelho-Amarelo distrófico arênico. Revista Brasileira de Ciência do Solo, Viçosa, v. 27, n. 6, p. 1013-1020, nov./dez. 2003.

SIQUEIRA, G. M.; VIEIRA, S. R.; CEDDIA, M. B. Variabilidade de atributos físicos do solo determinados por métodos diversos. Bragantia, Campinas, v. 67, n. 1, p. 203-11, 2008.

SONG, Z.; KIMBERLEY, M. O.; YUAN, H.; JIANG, H.; ZHOU, G.; WANG, H. Soil CO flux dynamics in the two main plantation forest types in subtropical China. Science of the Total Environment, Amsterdam, v. 444, p. 363-368, 2013.

SOUZA, E. D.; CARNEIRO, M. A. C.; PAULINO, H. B.; SILVA, C. A.; BUZETTI, S. Frações do carbono orgânico, biomassa e atividade microbiana em um Latossolo Vermelho sob Cerrado submetido a diferentes sistemas de manejos e usos do solo. Acta Scientiarum Agronomy. Maringá, v. 28, n. 3, p. 323-329, 2006.

TAVANTI, R. F. R.; MONTANARI, R.; PANOSO, A. R.; FREDDI, O. S.; PAZ-GONZÁLEZ, A. Pedotransfer function to estimate the soil structural " $\mathrm{S}$ " index and spatial variability in an Oxisol within a livestock farming system. Engenharia Agrícola, Jaboticabal, v. 28, p. 34-44, 2020.

VINHAL-FREITAS, I. C.; CORREA, G. F.; WENDLING, B.; BOBULSKÁ, L.; FERREIRA, A. S. Soil textural class plays a major role in evaluating the effects of land use on soil quality indicators. Ecological Indicators,[s.I.], v. 74, p. 182-190, 2017.

$\mathrm{XU}, \mathrm{M}$;; QI, Y. Soil surface $\mathrm{CO}_{2}$ efflux and its spatial and temporal variations in a young ponderosa pine plantation in northern California. Global Change Biology, Oxford, v. 7, p. 667-677, 2001.

\section{Contribuição de Autoria}

\section{1 - Paulino Taveira de Souza}

Engenheiro Agrônomo, Me., Doutorando em Agronomia https://orcid.org/0000-0003-4998-3602•paulinoagro@gmail.com

Contribuição: Conceituação, Curadoria de dados, Análise Formal, Visualização de dados, Escrita - primeira redação, Escrita - revisão e edição

\section{2 - Tatiane Carla Silva}

Engenheira Agrônoma, Ma., Doutoranda em Agronomia https://orcid.org/0000-0002-5317-9388•tcs.agronomia@gmail.com Contribuição: Conceituação, Escrita - primeira redação, Escrita - revisão e edição 


\section{3 - Maria Júlia Betiolo Troleis}

Engenheira Agrônoma, Ma., Doutoranda em Agronomia https://orcid.org/0000-0002-6402-0401•julia_troleis@hotmail.com

Contribuição: Conceituação, Curadoria de dados, Análise Formal, Visualização de dados, Escrita - primeira redação, Escrita - revisão e edição

\section{4 - Karla Nascimento Sena}

Engenheira Agrônoma, Ma., Doutoranda em Agronomia https://orcid.org/0000-0003-0437-8425•karlla_senna@hotmail.com

Contribuição: Conceituação, Curadoria de dados, Análise Formal, Visualização de dados, Escrita - primeira redação, Escrita - revisão e edição

\section{5 - Anne Caroline Rocha Silva}

Engenheira Agrônoma, Ma., Doutoranda em Agronomia https://orcid.org/0000-0003-1481-1560•anne.rocha@unesp.br

Contribuição: Conceituação, Curadoria de dados, Análise Formal, Visualização de dados, Escrita - primeira redação, Escrita - revisão e edição

\section{6 - Talles Eduardo Borges dos Santos}

Engenheiro Agrônomo, Dr., Professor

https://orcid.org/0000-0003-4221-2012•tallesunesp@yahoo.com.br

Contribuição: Conceituação, Curadoria de dados, Análise Formal, Visualização de dados, Escrita - primeira redação, Escrita - revisão e edição

\section{7 - Rafael Montanari}

Engenheiro Agrônomo, Dr., Professor

https://orcid.org/0000-0002-3557-2362•r.montanari@unesp.br

Contribuição: Conceituação, Curadoria de dados, Análise Formal, Visualização de dados, Escrita - primeira redação, Escrita - revisão e edição, Supervisão, Validação

\section{Como citar este artigo}

Souza, P. T.; Silva, T. C.; Troleis, M. J. B.. Sena, K. N.; Silva, A. C. R.; Santos, T. E. B.; Montanari, R. Variabilidade espacial da biomassa e atividade microbiana do solo sob sistema de integração lavoura-pecuária-floresta. Ciência Florestal, Santa Maria, v. 31, n. 4, p. 1949-1967, 2021. DOI 10.5902/1980509861902. Disponível em: https://doi.org/10.5902/1980509861902. 